\title{
Unpacking uncivil society
}

Incivility and intolerance in the 2018 Irish abortion referendum discussions on Twitter

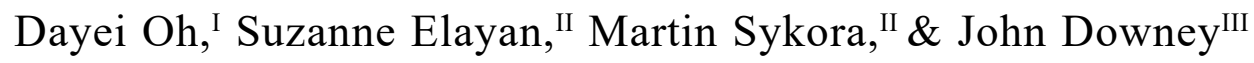 \\ I Online Civic Culture Centre (O3C), Loughborough University, UK \\ II Centre for Information Management (CIM), Loughborough University, UK

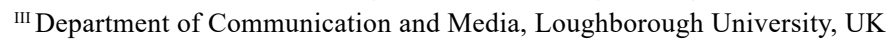

\begin{abstract}
In the era of rising populist sentiment, deep social and political polarisations, and a growing crisis of online harms, numerous scholars share concern about the impact of such uncivil populist forces on the health of liberal democracy. This article argues that we should first normatively distinguish between incivility and intolerance. We contend that the core problem of uncivil society is intolerance, not incivility. We then empirically analyse incivility and intolerance during the 2018 Irish abortion referendum and its discussions on Twitter by conducting a content analysis and qualitative textual analysis of 3,000 tweets posted between April and June 2018. The results show that despite selecting a highly emotive and polarised issue, incivility and intolerance do not dominate the Twittersphere. Furthermore, gender and political position of users were found to be associated with use of incivility and intolerance, which increased as the referendum approached.
\end{abstract}

Keywords: uncivil society, incivility, intolerance, Twitter public sphere, Irish abortion referendum

\section{Introduction}

Have our democracy and civil society turned into "uncivil society" or "bad civil society" (Ruzza, 2009)? In the era of rising populist sentiment, deep social and political polarisations, and a growing crisis of online harassment, abuse, threats, and discrimination, numerous scholars share the concern about the impact of such uncivil populist forces on the health of liberal democracy. Some scholars warn about uncivil society as a populist phenomenon that is essentially anti-pluralist, exclusionary, violent, and harmful to liberal democracy (Krzyżanowski \& Ledin, 2017; Ruzza, 2009). Other scholars suggest a more nuanced understanding of uncivil discourse, arguing that incivility in the form of rude, aggressive, and vulgar expressions in politics can be politically effective means, especially for the marginalised and disadvantaged in society who wish to call attention

Oh, D., Elayan, S., Sykora, M., \& Downey, J. (2021). Unpacking uncivil society: Incivility and intolerance in the 2018 Irish abortion referendum discussions on Twitter. Nordicom Review, 42(S1), 103-118. https://doi.org/10.2478/nor-2021-0009 
to issues ignored by the mainstream, and to mobilise civic participation (Jamieson et al., 2017; Rossini, 2019).

From this perspective, incivility should be distinguished from intolerance (Rossini, 2019). Some rhetorically uncivil and aggressive speech can be legitimate, such as passionate speech in feminist and anti-racist movements. At the same time, some seemingly civil and rational speech can be illegitimate, such as the white supremacist argument disguised as scientific facts and expertise. In other words, we suggest that what makes civil society uncivil is not rude and aggressive tone, but anti-pluralist and intolerant content, in a message. What is a "true threat" to democracy is intolerance, not incivility (Rossini, 2019).

With this article, we aim to contribute to such an effort to unpack uncivil society into incivility and intolerance through a case study of Ireland's 2018 abortion referendum discussions on Twitter. On 25 May 2018, Ireland held a referendum to decide whether to repeal the Eighth Amendment of the constitution that had criminalised abortion in Ireland. Whereas much research on populism has largely focused on nationalism, racism, and scepticism against multiculturalism (e.g., anti-immigration and asylum discourse in Austria and Sweden in Krzyżanowski \& Ledin, 2017; Trump administration and Brexit in Norris \& Inglehart, 2019; and EU-scepticism in Ruzza, 2009), abortion is also a highly worthwhile case to map the contours of hyper-polarised and anti-pluralist online uncivil discourse, given that anti-feminism is often part and parcel of the communicative style of populists. Similar to racial and ethnic issue-related populism, misogynistic and antiabortion populism largely entails "the cultural backlash" that channels the popular resentment of the conservatives against widespread and rapid "erosion" of traditional values and once widely accepted norms (e.g., religious teachings about sexual morality, chastity before marriage, traditional roles of women, and such) (Norris \& Inglehart, 2019). Moreover, abortion discussions include disruptive and disorderly voices of Irish and global feminists to change the country's repressive abortion policies. We employ content analysis and qualitative textual analysis of 3,000 tweets collected between April and June 2018. Our research questions explore the prevalence of incivility and intolerance and the relationship between the two, as well as their associations with other user demographics (e.g., gender and political position) and their use across time (i.e., between April and June).

As we argue, incivility and intolerance are two distinct concepts. In the Irish abortion discussions on Twitter, intolerant tweets are more likely to be incivil as well, but not vice versa. Intolerance is antidemocratic in that it marginalises and discriminates against groups of people and their views from a discussion, whereas incivility is more of an ambivalent tool that can be expressive and rhetorical on the one hand, and distressing and insulting on the other, or anywhere in between. This more nuanced, critical understanding of online uncivil discourse suggests that the core problem of uncivil society is intolerance, not incivility: incivility can be reasonable political rhetoric to serve pro-democratic goals, whereas intolerance is harmful to democratic principles of liberalism and pluralism.

\section{Conceptualising incivility as violations of politeness norms}

Incivility is largely theorised in terms of violations of social norms of politeness. Sociologist Erving Goffman's "face” theory (1982) is frequently borrowed by incivility researchers whose definition of incivility involves social norms of relationship and 
politeness (e.g., Muddiman, 2017; Stryker et al., 2016). In this regard, incivility is often operationalised as diverse forms of disrespectful, rude, and face-threatening speech, such as disparaging remarks at a person or group of people; disparaging remarks at a political idea, policy, or position; profanity and swear words; sarcastic mockery to convey contempt; and other rude and impolite remarks (Coe et al., 2014).

Incivility can be problematic to democracy (Papacharissi, 2004), because incivil attacks can be used to harass other users, forcing them to be silent or withdraw from a discussion due to distress or fear. Empirical studies have shown that incivility is often practiced against women as a kind of sexual harassment and online machismo (Duggan, 2014; Jamieson et al., 2017). The 2017 British report Intimidation in Public Life shows that parliamentary candidates who are female, Black, Asian, an ethnic minority, or LGBTQ + are disproportionately targeted for online intimidation and abuse (Committee on Standards in Public Life, 2017).

Nevertheless, condemning incivility as antidemocratic and anti-pluralist per se, solely based on politeness theories, can be misleading, as it undervalues the democratic potential of rude rhetoric in contentious politics where political disagreements are passionately debated. "Reasonable hostility", face-threatening attack, and political criticism are important for serving the needs of civil society (Tracy, 2008). Also, strict adherence to civility norms could subjugate and silence minority groups by tone-policing them without considering the actual content of the message (Jamieson et al., 2017; Milner \& Phillips, 2018). Politics is "not a level field", and some marginalised groups strategically rely on "disorderly, disruptive, annoying, and distracting means of communication" (Young, 2000: 50).

\section{Unpacking incivility and intolerance}

Incivility is not necessarily antidemocratic nor anti-pluralist per se. It is rather an ambivalent tool that contains different opportunities and agencies, and actors use incivility for different ends. For instance, "fuck" is a vulgar, incivil word, but we argue that using such a word to challenge perceived social injustice and to express one's empowerment (e.g., "fuck gender roles") or desire for empowerment cannot be dismissed, as the true democratic problem is discrimination against the socially marginalised (e.g., "fuck immigrants"). Arguably, herein incivility is being harnessed for democratic, not antidemocratic, purposes.

What is problematic and antidemocratic is intolerance (Rossini, 2019). Intolerance is incompatible with the democratic principles of liberalism and pluralism as it intends to exclude groups of people from political discussions and promotes discrimination. Furthermore, it hampers an extension of public services, social security, medical care, and so forth, based on a group's social, sexual, racial, ethnic, or religious characteristics. The reason expressions like "fuck immigrants" are antidemocratic is not because of the incivil word "fuck", but because of the intolerant, racist-nationalist ideology behind it.

Our codebook is developed upon these principles to treat incivility and intolerance as separate variables. This helps us to quantitatively analyse whether the discursive use of incivility and intolerance are empirically different. We also conduct an in-depth textual analysis to see if the use of incivility and intolerance are qualitatively different as well. A more detailed explanation of codebook development and coder training is discussed later. 
In this article, we aim to explore not only simply descriptive statistics of online incivility and intolerance, but also the in-depth, nuanced texture of incivility and intolerance. The first research question, in three parts, addresses the descriptive side of the research:

RQ1a. How much incivility and intolerance is present in online political discussions of the Irish abortion referendum?

RQ1b. Who is incivil and intolerant in terms of user demographics?

RQ1c. How does the use of incivility and intolerance change as the referendum progresses?

With the second research question, we explore the relations between incivility and intolerance: do they co-occur frequently? If so, it might be the case that although incivility and intolerance are theoretically different - that is, that one is more to do with tone and the other with content - at an empirical level, they are almost inseparable.

RQ2. What are the relations between incivility and intolerance?

Finally, it is necessary to take a more micro-analytical approach to the characteristics of incivility and intolerance in order to examine the way that they are used by different speakers. The third, qualitative research question can complement the more quantitative questions above, by explaining in depth how pro- and anti-choice users resort to incivility and intolerance. In particular, this qualitative analysis would show how some incivilities can be antidemocratic while others are not, as well as how some incivility can even be democratically justifiable and legitimate.

RQ3. What are the qualitative characteristics of incivil and intolerant tweets?

\section{Method}

\section{Sample}

For the purpose of this study, we explore the 2018 Irish abortion referendum discussions on Twitter to look at incivility and intolerance around abortion policy discussions. Abortion discourse is a suitable topic to look at diverse incivil and intolerant remarks, as it is a sensitive and highly polarised sociopolitical issue. Also, this referendum is an appropriate choice to examine online incivility and intolerance, since social media platforms such as Twitter have served as sites of negative language, used by both proand anti-choice sides (Sweeney, 2018). There were accusations during the referendum that numerous "trolls" were undermining the integrity of the referendum, which caused social media platforms such as Facebook to ban foreign accounts outside Ireland that were spreading dark ads (Hern, 2018). Twitter introduced new measures to fight spam, abuse, trolls, and hateful conduct, suspending an average of 17,000 accounts per day in May 2018 (Roth \& Harvey, 2018).

To examine incivility and intolerance in the referendum discussions, we use a Twitter dataset shared on Harvard Dataverse (Littman, 2018). This dataset contains 2,279,396 tweets collected between 13 April and 4 June 2018. The rehydrated dataset contains $1,842,370$ tweets; the lost tweets are due to how Twitter APIs and platform works. ${ }^{1}$ We randomly sampled a sub-dataset of 3,000 tweets for manual content analysis and 
qualitative textual analysis. The sample size was motivated and decided upon after surveying other online incivility research and Twitter content analysis works (e.g., Coe et al., 2014; Kim et al., 2018; Papacharissi, 2004; Rowe, 2015; Rossini, 2019). Also, we chose random sampling, as several studies have found that simple random sampling is an efficient strategy to obtain a representative sample, in terms of topic saturation, of the entire dataset (Kim et al., 2018; Le et al., 2019).

For ethical social media research, this article does not directly quote any tweet in the sample. Due to the searchability of Twitter, we paraphrase tweets in order to prevent the tweets from being reverse searched and the author being identified. However, such paraphrasing is minimal so as not to distort the unique utterance of incivility and intolerance.

\section{Content analysis}

This study employs systematic content analysis (Neuendorf, 2002) with the codebook (available upon request) developed by two researchers operating on two units of analysis: users and tweets. Users were coded in terms of gender (female, male, unidentifiable) and their political position vis-à-vis abortion (pro-choice, anti-choice, or unidentifiable). The gender of the users was coded based on their first name in their profile. This has a limitation in that some names are gender-neutral and some users use genderunidentifiable pseudonyms (e.g., Old Glory). In such cases, their gender was coded as gender unidentifiable.

Political position was coded in terms of the hashtags used in the tweet as well as the overall argument of the tweet. The list of hashtags includes the following: 32 prochoice (e.g., \#trustwomen, \#repealthe8th, \#Together4Yes, \#voteyes); 14 anti-choice (e.g., \#JoinTheRebellion, \#savethe8th, \#loveboth, \#lifecanvass); and 7 neutral and ambiguous hashtags (e.g., \#8thref, \#HomeToVote, \#8thamendment, \#hometocanvass, \#abortionreferendum). Some tweets have both pro- and anti-choice hashtags, and some do not have any hashtags; in such cases the coders read the overall argument of the tweet and coded whether it was written for or against abortion rights.

Tweets were coded to identify whether they contain incivility and intolerance. The unit of coding was at individual tweet level, and considered hyperlinks, images, and audio-video clips included in a tweet - and other tweets if a collected tweet was a part of a thread made by the same user.

The coding of the 3,000 tweets was undertaken by one coder, but two coders have partaken in the process of codebook development and coder training to test inter-coder reliability. They tested 5 per cent of the sample $(n=150)$ during several rounds of training, revision, and retesting. Reliability for all individual variables in the final version of the codebook achieves substantial agreement in terms of both Cohen's kappa (.75 average) and per cent agreement (93\% average). ${ }^{2}$ The incivility variable has 93 per cent agreement and .76 kappa, and intolerance has 94 per cent agreement and .74 kappa. Per cent agreement is used to complement the overly conservative measure of beyond-chance agreement of Cohen's kappa (Joyce, 2013).

This study needed multiple "consensus binding discussions" (Neuendorf, 2002: 134) among coders to produce very specific rules to code incivility and intolerance in direct relation to abortion discourse. Discussions were necessary to achieve high inter-coder agreement, because although incivility and intolerance are largely commonsensical 
and socially shared concepts, they also have individual variances. Many would have a shared notion at an abstract level of what incivility and intolerance are (e.g., swearing in political discussions is incivil, denying others' liberty and rights are intolerant), but there could be many disagreements at an empirical level (e.g., Is "bloody" an incivil word? Is it intolerance to call pro-choice women "baby murderers"?). Having consensus-binding discussions creates more practical rules that can apply to code more common, mundane forms of incivility and intolerance that is particular to the Irish abortion discourse.

\section{Qualitative textual analysis}

Qualitative textual analysis was conducted to examine the ways incivility and intolerance are used by different pro- and anti-choice users and users whose political positions are neutral or ambiguous. Such qualitative in-depth analysis is crucial to developing a thorough understanding of the phenomenon, which cannot be grasped solely by statistical analysis. Qualitative textual analysis enables situated analysis of how incivility and intolerance are expressed and substantiates how the use of incivility and intolerance are different.

\section{Results}

The final size of the analysis is 2,949 tweets, sifting out 51 irrelevant tweets that used Irish abortion referendum related hashtags to talk about other political agendas (for example, \#voteyes to talk about the Scottish independence referendum). Table 1 shows the overall distribution of gender and political position in the sample. The sample of the Irish abortion discussion on Twitter is led by users with female names $(n=1,122)$, followed by gender-unidentifiable names $(n=1,085)$ and male names with the least $(n$ $=742)$. Pro-choice tweets dominated the sample $(n=2,237)$, followed by anti-choice $(n=496)$ and neutral or ambiguous $(n=216)$.

Chi-square tests show that gender and positions have statistically significant association $\left(\chi^{2}=36.497, p<.001\right)$ - although the strength of such association at an empirical level is rather negligible $(\varphi=.111)$ (Glen, 2016). The sample has more pro-choice tweets written by users with female names $(81 \%)$ than male names $(71 \%)$ and gender-unidentifiable names (74\%). In contrast, users with male and gender-unidentifiable names post more anti-choice tweets (19\% of male; and $20 \%$ of gender-unidentifiable users) than users with female names (13\%). Also, users with male names exhibit a more neutral and ambiguous stance on abortion (10\%) than users with female $(6 \%)$ and gender-unidentifiable $(7 \%)$ names. In a nutshell, most women, men, and other users in the sample are pro-choice. But in a statistical comparison, users with female names hold pro-choice views more frequently than users with male names, and users with male names tweet more anti-choice, neutral, and ambiguous views than users with female names. 
Table 1 Distribution of gender and political position in the sample

\begin{tabular}{llll}
\hline & Pro-choice & Anti-choice & Unidentifiable \\
\hline Female (total = 1,122) & $912(81 \%$ within gender, & $143(13 \%$ within gender, & 67 (6\% within gender, \\
& $41 \%$ within position) & $29 \%$ within position $)$ & $31 \%$ within position $)$ \\
Male (total = 742) & $528(71 \%$ within gender, & $139(19 \%$ within gender, & 75 (10\% within gender, \\
& $24 \%$ within position) & $28 \%$ within position $)$ & $35 \%$ within position $)$ \\
Unidentifiable (total = 1,085) & $797(74 \%$ within gender, & $214(20 \%$ within gender, & 74 (7\% within gender, \\
& $36 \%$ within position) & $43 \%$ within position $)$ & $34 \%$ within position $)$ \\
\hline Total & 2,237 & 496 & 216 \\
Chi-square $\left(\chi^{2}\right)$ & $36.497^{\star \star *}$ & & \\
Phi $(\varphi)$ & .111 & & \\
\hline
\end{tabular}

${ }^{\star} p<.05,{ }^{\star \star} p<.01,{ }^{\star \star \star \star} p<.001$

\section{Mapping incivility and intolerance}

Our first research question asks what the mapping of incivility and intolerance is. It turns out that incivility and intolerance do not account for the majority of the Twitter discussions. Overall, only 14 per cent $(n=413)$ of tweets contain incivility, and 5 per cent $(n=138)$ include intolerance. In short, there is neither a substantial amount of incivility nor intolerance in Irish abortion policy discussions on Twitter.

These percentages are interestingly lower than the substantial amount of online incivility and intolerance other international research has found: for example, Coe and colleagues's (2014) study finds that in the comment section in an American local newspaper website, more than one in five comments (22\%) contain incivility. Rossini's (2019) study on a Brazilian Facebook page and newspaper websites finds that the presence of incivility is substantial both on Facebook and the websites (41\% in the news websites and $37 \%$ on Facebook) although the presence of intolerance is much less frequent $(10 \%$ on Facebook and $4 \%$ on news websites). Their findings are not directly comparable to this article's context of the Irish abortion discourse on Twitter, but such disparities require further exploration in this matter: Could the low presence of incivility and intolerance in the Irish Twitter discussions be attributed to Ireland's online civic culture, the nature of abortion discussions, or our method? Another aspect to be taken into account is that there were tweets lost during the rehydration process. When we were rehydrating the dataset in March 2019, we were not able to retrieve 437,026 tweets. This might have been because some users themselves deleted their tweets or changed their accounts to private, or because Twitter deleted and suspended accounts that violated Twitter guidelines. Despite the loss of some tweets, it does not pose enough of a problem as to invalidate our findings, because the size of the rehydrated dataset is still massive and accounts for 80 per cent of the original dataset.

In terms of the relationship between gender and online uncivil discourse, our analysis shows that gender has statistically meaningful relationships with both incivility $\left(\chi^{2}=9.707, p<.01\right)$ and intolerance $\left(\chi^{2}=7.960, p<.05\right)$ (see Table 2$)$. In terms of incivility, it is inferable that users with female names use incivility less frequently than users with male and gender-unidentifiable names. Users with female names have the lowest percentage of incivility within each gender pool: 12 per cent of female tweets 
are incivil, whereas 16 per cent of male tweets and 15 per cent of gender-unidentifiable tweets are incivil. It is interesting that even though the overall discussion is largely led in terms of numbers by users with female names $(1,122$ tweets by female names and 742 by male names), it is users with male names who use incivil language more on average.

Similar inferences can be made in the analysis of intolerance as well. Users with female names use intolerance less frequently than users with male names and especially less than users with gender-unidentifiable names. 3 per cent of tweets by users with female names contain intolerance, whereas 5 per cent of tweets by male-name users and 6 per cent of tweets by gender-unidentifiable users include some form of intolerance. However, the effect size of such association might not be significant at a practical level (incivility $\varphi=.057$; intolerance $\varphi=.052$ ) (Glen, 2016). Taken together, it might be suggested that gender is related to the tendency to be more readily incivil and intolerant, but not to such a large extent.

Table 2 Prevalence of incivility and intolerance based on gender of the users

\begin{tabular}{lll}
\hline & Incivility & Intolerance \\
\hline Female $(n=1,122)$ & $\begin{array}{l}129(12 \% \text { within gender, 31\% within } \\
\text { incivility })\end{array}$ & $\begin{array}{l}37(3 \% \text { within gender, 27\% within } \\
\text { intolerance })\end{array}$ \\
Male $(n=742)$ & $\begin{array}{l}119(16 \% \text { within gender, } 29 \% \text { within } \\
\text { incivility })\end{array}$ & $\begin{array}{l}39(5 \% \text { within gender, 28\% within } \\
\text { intolerance })\end{array}$ \\
Unidentifiable $(n=1,085)$ & $\begin{array}{l}165(15 \% \text { within gender, } 40 \% \text { within } \\
\text { incivility })\end{array}$ & $\begin{array}{l}62(6 \% \text { within gender, 45\% within } \\
\text { intolerance })\end{array}$ \\
\hline Total & 413 & 138 \\
Chi-square $\left(\chi^{2}\right)$ & $9.707^{\star \star}$ & $7.960^{\star}$ \\
Phi $(\varphi)$ & .057 & .052 \\
\hline
\end{tabular}

${ }^{\star} p<.05,{ }^{\star \star} p<.01,{ }^{\star \star *} p<.001$

We also examine incivility and intolerance in relation to users' political positions (see Table 3). These results indicate that the political positions of Twitter users have significant associations with both incivility $\left(\chi^{2}=37.269, p<.001, \varphi=.112\right)$ and intolerance $\left(\chi^{2}=313.463, p<.001, \varphi=.326\right)$. Anti-choice users use incivility more often, and use intolerance considerably more often, than pro-choice users and users whose positions are neutral or ambiguous. This is another interesting finding. Although the landscape of the Irish abortion discussion on Twitter is largely pro-choice dominant (2,237 prochoice tweets and 496 anti-choice tweets), it is the anti-choice tweeters who are more frequently incivil and intolerant. Within the positions, 23 per cent of anti-choice tweets $(n=112)$ contain incivility and 20 per cent involve intolerance $(n=99)$, which means that one in every five anti-choice tweets contains some form of incivility and intolerance. This amount is substantially larger than the amount of incivility and intolerance in pro-choice tweets $(13 \%[n=279]$ and $2 \%[n=39]$ respectively).

So, here, we can see a pattern. We have analysed above that users with male names hold anti-choice views more often than users with female names. This means that male names and anti-choice views overlap to some extent, and they - who are minority in number in the Irish abortion discussions - tend to express more incivil and intoler- 
ant tweets. This suggests that there is a relationship between the form and content of populist communication. It is plausible to suggest that these incivil and intolerant tweets express "the cultural backlash" from conservatives, who were presented with a discursive opportunity to express their feelings of resentment, anger, and a sense of loss and be susceptible to misogynistic, sexist, and other intolerant appeals (Norris \& Inglehart, 2019).

Table 3 Prevalence of incivility and intolerance based on political positions of the users

\begin{tabular}{lll}
\hline & Incivility & Intolerance \\
\hline Pro-choice $(n=2,237)$ & $\begin{array}{l}279(13 \% \text { within position, 68\% within } \\
\text { incivility })\end{array}$ & $\begin{array}{l}39(2 \% \text { within position, 28\% within } \\
\text { intolerance }\end{array}$ \\
Anti-choice $(n=496)$ & $\begin{array}{l}112(23 \text { within position, } 27 \% \text { within } \\
\text { incivility })\end{array}$ & $\begin{array}{l}99(20 \% \text { within position, } 72 \% \text { within } \\
\text { intolerance })\end{array}$ \\
Unidentifiable $(n=216)$ & $\begin{array}{l}22(10 \% \text { within position, } 5 \% \text { within } \\
\text { incivility })\end{array}$ & $\begin{array}{l}0(0 \% \text { within position, 0\% within } \\
\text { intolerance })\end{array}$ \\
\hline Total & 413 & 138 \\
Chi-square $\left(x^{2}\right)$ & $37.269^{\star \star *}$ & $313.463^{\star \star \star}$ \\
Phi $(\varphi)$ & .112 & .326 \\
\hline
\end{tabular}

${ }^{\star} p<.05,{ }^{\star \star} p<.01,{ }^{\star \star \star} p<.001$

Finally, we explore how the use of incivility and intolerance changes across the time of the abortion referendum debates from April to June 2018. Our chronological analysis shows that total participation and incivil and intolerant tweets drastically increased from 24 May, a day before the vote. The figures below (Figure 1 and 2) indicate that substantial amounts of tweets were made over a period of three days: 24-26 May, a day before the vote until a day after the vote. The day of the vote had the highest number in terms of participation, incivility, and intolerance. Of all referendum tweets, 44 per cent $(n=1,302)$ were made in these three days; so were 34 per cent of incivil tweets $(n$ $=141)$ and 30 per cent of intolerant tweets $(n=41)$.

We can infer that incivility and intolerance are political and contextual products rather than intrinsic personality traits. Incivility and intolerance are heated expressions of political and ideological beliefs and populist sentiments, probably as a last spurt to promote a side to win the referendum on 24 and 25 May - and additionally, expressions of emotions - excitement or frustration and resentment - when users have discovered their side has won or lost in the referendum on 26 May. Even when debating such an emotive topic as abortion, it was only during the final day and in the immediate aftermath that discourse took an incivil and intolerant turn. However, it should be noted that the similarities between the 3,000-tweet sample and the 1.8+ million-tweet dataset have not been tested, and this analysis may not be representative of the entire dataset, nor of the complete abortion discourse at a national scale. 
Dayei Oh, Suzanne Elayan, Martin Sykora, \& John Downey

Figure 1 Number of sample tweets, April-June 2018

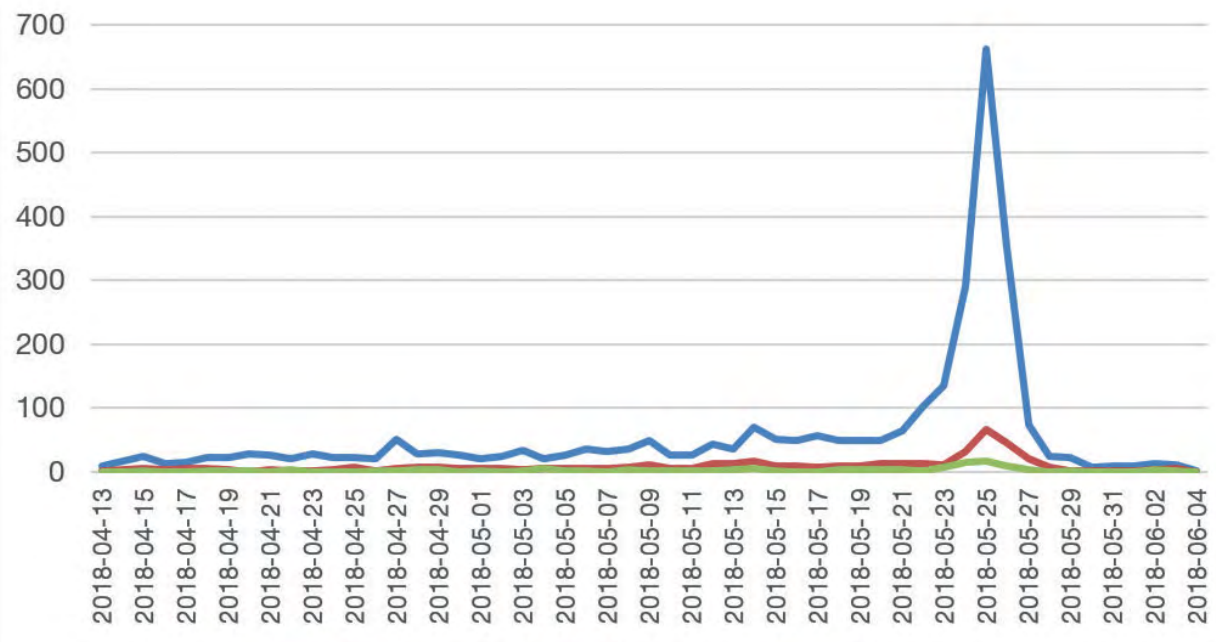

-Total tweets Incivility Intolerance

Comments: The figure shows the distribution of the tweets $(n=2,949)$ during the data collection (13 April to 4 June). The number of overall participation had its peak on 25 May, the referendum voting day. A day before (24 May) and a day after the voting day (May 26) also had increased participations than other days. 44 per cent of the total tweets $(n=1,302)$ were made during these three days.

Figure 2 Number of incivil and intolerant tweets, April-June 2018

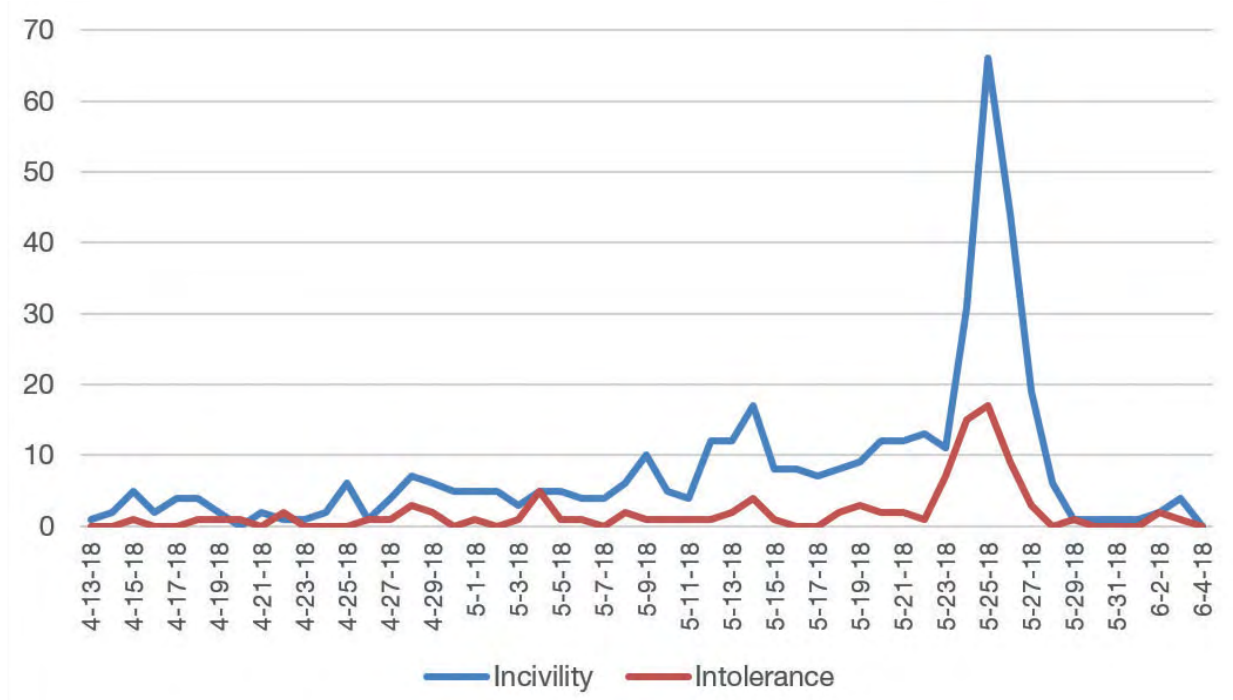

Comments: The figure shows the distribution of the incivil $(n=413)$ and intolerant tweets $(n=138)$ during the data collection ( 13 April to 4 June). The number of incivil and intolerant tweets had their peaks on 25 May, the referendum voting day. A day before ( 24 May) and a day after the voting day ( 26 May) also had an increased number of incivility and intolerance than other days. 34 per cent of the incivil tweets $(n=141)$ and 30 per cent of intolerant tweets $(n=41)$ were made in these three days.

\section{Distinguishing incivility from intolerance}

Our second research question asks whether incivility and intolerance are distinct concepts. The results suggest that they are, although they co-occur on occasion. Table 4 highlights that 36 per cent of intolerance entails incivility, whereas it is 12 per cent of 
the incivil tweets in the sample $(n=49)$. This indicates that intolerant tweets are more likely to be incivil and intolerant at the same time, but not vice versa $\left(\chi^{2}=55.580, p<\right.$ $.001, \varphi=.137)$.

Furthermore, interestingly, two-thirds of the intolerant tweets are not incivil ( $n=89$, $65 \%$ of intolerance) - which means that they have exclusionary and intolerant messages, but disguise themselves in a rational and civil tone. This substantiates the main argument of the article - what is problematic in uncivil society is the intolerant content - and less the incivil tone - of political communications.

Table 4 Crosstabulation of incivility and intolerance

\begin{tabular}{llll}
\hline & Tolerant & Intolerant & Total \\
\hline Civil & $2,447(97 \%$ within incivility, $87 \%$ & $\begin{array}{l}89(4 \% \text { within incivility, } 65 \% \\
\text { within intolerance })\end{array}$ & 2,536 \\
Incivil & $\begin{array}{l}364(88 \% \text { within incivility, } 13 \% \\
\text { within intolerance })\end{array}$ & $\begin{array}{l}49(12 \% \text { within incivility, } 36 \% \\
\text { within intolerance })\end{array}$ & 413 \\
& 2,811 & 138 \\
Total & $55.580^{\star \star \star}$ & & \\
Chi-square $\left(\chi^{2}\right)$ & .137 & & \\
Phi $(\varphi)$ & & \\
\hline
\end{tabular}

${ }^{\star} p<.05,{ }^{\star \star} p<.01,{ }^{\star \star \star *} p<.001$

\section{Qualitative textual analysis of incivility and intolerance}

This qualitative analysis is part of a still ongoing effort for Dayei Oh's doctoral project, and in this article, we only include a limited range of preliminary findings. Qualitative textual analysis shows that incivility as a tone has some ambiguous potential that can serve both for and against democracy. Incivility can be rhetorical and expressive (reasonable), or harassing and distressing (unreasonable). On the other hand, intolerance is antidemocratic and anti-pluralist.

One of the most popular deployments of reasonable incivility is to call out perceived social injustice in a legal system, society, and culture. Pro-choice users, especially, employ incivility for this purpose, criticising the "archaic", "illiberal", "barbaric", and "cruel" anti-abortion laws in Ireland. Anti-choice users - although not as extensively as those who are pro-choice - also passionately and aggressively criticise contemporary society, which is heading downhill to a "shameful", "vampire and clown" "cult of death" that does not recognise the sanctity of human life.

Reasonable incivility is also used from both pro- and anti-choice sides to condemn opposing institutions and opposing groups of people. Many pro- and anti-choice incivilities target major institutions, such as the government, political parties, the Catholic Church, mass media, and so forth. Even when users criticise groups of citizens, they tend to attack a group of people as a collective entity (e.g., "those campaigners are disgusting"), instead of harassing and insulting individual users in a direct way (e.g., "you are disgusting"). Furthermore, users often attack the ideas, arguments, and actions of their opponents that are relevant to the abortion discussion, instead of attacking their opponents' personal attributes. This corroborates the finding of previous incivility research that the public distinguish personal- and public-level incivility (Muddiman, 2017), as well as personal attack and issue-based attack (Stryker et al., 2016). 
Moreover, reasonable incivility is a way to assert one's determination and provide empowerment for marginalised actors, such as women. Even though abortion and crisis pregnancies are women's issues, Irish women's voices and lived experiences have been largely peripheralised and silenced in the andro-centric public spheres of religion and politics (Earner-Byrne \& Urquhart, 2019). Breaking the long silence, Irish pro-choice women tweeted empowering statements like "Shove it up your ass, we will not back down!", "Get your hands off my fucking uterus", "Don't fucking dare to tone-police us", and so forth. Such incivil rhetoric is chosen by women to make their voices heard and recognised and to express their determination and resilience. Such expressive incivility is different from insulting incivility, which is used to distress and harass a specific individual with vulgar names and swear words.

This analysis of reasonable incivility is not an exhortation to being incivil and hostile to each other, but rather to acknowledge the rhetorical function of incivility in the sites of political struggles. Zerilli provides a feminist analysis of incivility in that the trope of civility is often deployed against feminist and anti-racist arguments. She adds:

Uncivil public behaviour is symptomatic of a more general democratic deficit of public space in which grievances can legitimately be raised and meaningfully addressed by fellow citizens and their elected representatives. If some citizens are more prone to shout, that may well be because those in power are not listening. (Zerilli, 2014: 112)

In the sample, there is problematic and unreasonable incivility that operates as menace, abuse, and distressing attacks at named individuals. For instance, both pro- and anti-choice tweets sometimes call opponents harsh names, such as "Fucking gobshite", "Communist scumbag feminist goblins", "Spineless cowards", and so forth. Some tweets express threatening remarks at politicians, public figures, and users with opposing views, such as "Get in the sea", "Crawl under a rock", and so forth. Such hostile antagonism does not contribute to the deliberative and persuasive side of the public sphere and civil society and should be discouraged.

However, some incivility lies between menace and humour. A pro-choice tweet, for example, says "Get in the sea if you are so fond of forcing people to have to cross the sea to get abortion". Is "get in the sea" in this tweet an online joke to signal disdain, or a threat and harassment to tell someone to drown themselves (equivalent to "Go kill yourself')? There were some precedent cases where online menace and jokes are indiscernible. In 2016 in the UK, Labour Party member of parliament Thangam Debbonaire accused a University of Bristol student of sending her a death threat - "Get in the sea" - on Twitter. While the university agreed with Debbonaire and disciplined the student to write a formal letter of apology, others criticised Debbonaire for overreacting to a popular online joke (Tait, 2016). Overall, qualitative analysis of incivil tweets show that the distinction between reasonable and unreasonable incivility cannot be sharply made and needs further deliberation.

In contrast, intolerance is anti-pluralist and antidemocratic. Many intolerant tweets enter the abortion discussion in bad faith. The worldview of the intolerant users involves a simplistic moral dualism where "we" are righteous, good, and represent deliverance, and "they" are immoral, evil, and represent demise. In doing so, inter-group conversation or compromise seems undesirable or nearly impossible. 
In their demonising rhetoric, intolerant anti-choice tweets compare pro-choice users to "the devil", "Satan", "Nazi", and "Hitler", and compare abortion to "killing", "murder", "slaughter", and "holocaust". Some intolerant pro-choice tweets also use the Nazi trope to demonise the anti-choice side (e.g., "his language is reminiscent of Nazi propaganda"). Nazi analogies can be inappropriate hyperbolic comparisons and argumentative fallacies if the association is based on superficial similarities (e.g., Nazi accepted X. Group Y accepts X. Therefore, Y is Nazi) (Curtis, 2004). Only a thorough comparison of history and political ideologies between Nazism and one's opponents can make the Nazi trope more than an unreasonable and fallacious intolerance.

Furthermore, a couple of pro-choice tweets use the trope of Islam and its fundamentalist terrorist organisations to demonise opposing political parties and politicians (e.g., "misogynistic like the Taliban" and "While shouting for abortion and LBGTQ+ rights, he promotes the Muslim Brotherhood and Hamas who slaughter LGBTQ+ and their babies to death"). Similar to the Nazi trope, such Islamic fundamentalist analogies can be antidemocratic in that they exacerbate antagonistic polarisation between "us" and "them" based on fallacious logic. For instance, an Irish politician supporting an Irish-Palestine solidarity campaign was denigrated as promoting Islamic fundamentalist groups and their intolerant anti-LGBTQ+ crimes. The association between supporting Palestine and promoting Islamic fundamentalism and their anti-LGBTQ+ crime lacks rigorous analysis of politics and ideologies. The superficial intolerant analogy simply derails deliberation by shunning any reasonable contribution from the person denounced as an "Islamic terrorist sympathiser". It also reproduces the discriminatory representation of Islam as extremism and violence, which can further marginalise the Muslim communities living in Ireland and Europe.

Lastly, some of the intolerant anti-choice tweets are not just intolerant of abortion rights, but they express their rejection of other liberal changes in sociocultural values and non-conventional lifestyles, such as LGBTQ+ rights; for example, criticising a sex education bill for "promoting abortion", "peddling the myth that there are more than two genders" and "explaining how two men have sex" to "our" children. These tweets demonstrate the deep entanglement between anti-abortion intolerance, anti-liberal backlash from social conservatives, and the rise of populism, which reaffirms that anti-abortion and anti-feminism are often part and parcel of the bigger populist phenomenon.

\section{Conclusions}

Our research has explored the prevalence and the use of incivility and intolerance in the 2018 Irish abortion referendum discussions on Twitter, in order to enhance our understanding of the extent to which uncivil online discourse is incivil, intolerant, or both. First, our research is at odds with a common finding of previous incivility research regarding the substantial amount of incivil and intolerant speech in online discussions (e.g., Coe et al., 2014; Rossini, 2019). In our analysis of Twitter discussions in Ireland, the results show that despite selecting a highly emotive and polarised issue, incivility and intolerance do not dominate the Twitter public sphere.

This article cannot provide a decisive explanation of the disparity between the low percentages of incivility and intolerance in our sample and the higher proportion of these in previous research, such as Coe and colleagues' (2014) and Rossini's (2019). This 
might be to do with platform differences: Coe and colleagues' sample is an American local newspaper website and Rossini's is a Brazilian Facebook page and news sites. Our sample is Twitter, whose user demographics tend to have higher education qualifications and higher income than the average public (Wojcik \& Hughes, 2019). These different user demographics might have impacted the research findings. In other respects, such disparities might have to do with cross-cultural differences between the European political landscape and online civic culture (Ireland) and those on the American continents (the US and Brazil). If not, it might relate to abortion discourse in particular. Future comparative research can explore such a gap. Dayei Oh has been collecting US Twitter data in relation to the current abortion ban attempts in the US to compare incivility and intolerance between Ireland and US abortion discussions.

Incivility and intolerance in the Irish abortion discussions on Twitter share several findings from previous research. First, we found that users with male names use incivility and intolerance more than users with female names. This seems to align with "different voice ideology" (Cameron \& Shaw, 2016), to think women by nature have different speech styles from men: eschewing aggressive speech style and preferring cooperative and supportive speech. However, we encourage the reading of our findings in a careful way and refraining from a biologically essentialist argument that this "different" style "comes naturally" to women (Cameron \& Shaw, 2016: 134). Cameron and Shaw, analysing women and men candidates' television debate and speech styles during the 2015 British General Election, argue that there is no clearly gendered pattern of political speech styles among women and men. Instead, women candidates use different styles strategically and their speech styles are more to do with their political experiences and party status (major or minor party). Here, in our sample, we see that users with male names overlap with users with anti-choice views to some extent, who are both minority in number and who have a sense of resentment of the "growing threats" to traditional Irish values (i.e., the rise of secularism, feminism, and pro-choice sentiment against the traditional Catholic values). The resort to incivility and intolerance of the male-name users in the sample might be more closely related to reactionary populist tendencies than their gender.

Such an interpretation of our findings confirms previous discussions that uncivil, outrageous, and populist speech is more prevalent in conservative, right-wing discourse, although liberal left-wing discourse is not free from this concern (Berry \& Sobieraj, 2013). Further to this, we found that the use of incivility and intolerance varied depending on the stages of the referendum, and peaked from a day before the vote, which could be seen as a sort of last spurt for users' cause to win the referendum. This aligns with previous findings that incivility is less a personal or habitual trait and driven more by context (Coe et al., 2014) - a rhetorical choice to serve communicative purposes in a given situation.

The second part of the article discussed incivility and intolerance as distinct concepts. They are theoretically different because incivility does not necessarily violate democratic principles of liberalism and pluralism, whereas intolerance is incompatible with such norms. Empirically, intolerant tweets are more likely to be incivil at the same time, but not vice versa, which confirms the assumption that they are different concepts but can empirically co-occur.

Qualitative textual analysis also substantiates the claim that incivility can be used for pro-democratic purposes - such as criticising injustice, emphasising a point, em- 
powering, and mobilising civic participation - whereas some forms of incivility can be unreasonable intimidation, harassment, and abuse. However, distinction between reasonable and unreasonable incivility is not a strict list of dos and don'ts yet, and it requires further discussions. Meanwhile, intolerance is frequently used to demonise and marginalise a group of people and their views with unreasonable prejudices and hatred (see also Rossini, 2019).

Finally, it is important to note the methodological limitations of our article. The sample of 3,000 tweets may neither be statistically representative of the entire dataset of more than 1.8 million tweets, nor a thorough representation of the Irish abortion discourse at a national scale. It is, however, enough for the aim of this article to provide an emergent discussion about unpacking uncivil discourse into incivility and intolerance through an explorative case study. Moreover, we plan to keep exploring the dataset using computational methods to make full use of the magnitude of the dataset and find innovative ways to research uncivil society at a big data scale.

Various possibilities of future research can add more insightful discussions about understanding incivility and intolerance. Future research could involve conducting a comparative platform study to assess and compare prevalence and use of incivility and intolerance on Twitter and other social media platforms, such as Facebook. Future research could also conduct cross-cultural studies in order to see similarities and differences between uncivil discourses across the world. Such research would help further illuminate the strategic employment of incivility and intolerance in our online political discourse.

\section{Notes}

1. For official information, see Twitter developer at https://developer.twitter.com/en/docs/tweets/post-andengage/api-reference/get-statuses-lookup

2. We have also calculated Krippendorff's alpha, which was equivalent to the Cohen's kappa reported here, achieving substantial level of agreement.

\section{References}

Berry, J. M., \& Sobieraj, S. (2013). The outrage industry: Political opinion media and the new incivility. New York: Oxford University Press.

Cameron, D., \& Shaw, S. (2016). Gender, power and political speech: Women and language in the 2015 UK general election. London: Palgrave Macmillan.

Coe, K., Kenski, K., \& Rains, S. A. (2014). Online and uncivil? Patterns and determinants of incivility in newspaper website comments. Journal of Communication, 64(4), 658-679. https://doi.org/10.1111/jcom.12104

Committee on Standards in Public Life. (2017, December). Intimidation in public life. www.gov.uk/government/organisations/the-committee-on-standards-in-public-life

Curtis, G. N. (2004). Logical fallacy: The Hitler card. Fallacy files. http://www.fallacyfiles.org/adnazium. html\#Note 1

Duggan, M. (2014, October 22). Online harassment. Pew Research Centre. https://www.pewinternet. org/2014/10/22/online-harassment/

Earner-Byrne, L., \& Urquhart, D. (2019). The Irish abortion journey, 2019-2018. London: Palgrave Macmillan. https://doi.org/10.1007/978-3-030-03855-7

Glen, S. (2016). Phi coefficient (mean square contingency coefficient). Statistics how to. https://www.statisticshowto.com/phi-coefficient-mean-square-contingency-coefficient/

Goffman, E. (1982). Interaction ritual: Essays on face-to-face behaviour. New York: Pantheon Books.

Hern, A. (2018, May 8). Facebook to block foreign spending on Irish abortion vote ads. The Guardian. https:// www.theguardian.com/world/2018/may/08/facebook-to-block-foreign-spending-on-irish-abortion-voteads-referendum

Jamieson, K. H., Volinsky, A., Weitz, I., \& Kenski, K. (2017). The political uses and abuses of civility and incivility. In K. Kenski, \& Jamieson, K. H. (Eds), The Oxford handbook of political communication (pp.205218). New York: Oxford University Press. https://doi.org/10.1093/oxfordhb/9780199793471.001.0001 
Joyce, M. (2013). Picking the best intercoder reliability statistic for your digital activism content analysis. http://www.bwgriffin.com/gsu/courses/edur9131/content/IntercoderReliabilityBlogPost.pdf

Kim, H., Jang, S. M., Kim, S. \& Wan, A. (2018). Evaluating sampling methods for content analysis of Twitter data. Social Media + Society, 4(2), 1-10. https://doi.org/10.1177/2056305118772836

Krzyżanowski, M., \& Ledin, P. (2017). Uncivility on the web: Populism in/and the borderline discourses of exclusion. Journal of Language and Politics, 16(4), 566-581. https://doi.org/10.1075/jlp.17028.krz

Le, G. M., Radcliffe, K., Lyles, C., Lyson, H. C., Wallace, B., Sawaya, G., Pasick, R., Centola, D., \& Sarkar, U. (2019). Perceptions of cervical cancer prevention on Twitter uncovered by different sampling strategies. PloS one, 14(2), https://doi.org/10.1371/journal.pone.0211931

Littman, J. (2018). Ireland 8th Tweet Ids. [dataset]. Harvard Dataverse. https://doi.org/10.7910/DVN/PYCLPE

Milner, R. M., \& Phillips, W. (2018, November 20). The Internet doesn't need civility, it needs ethics. Motherboard. https://www.vice.com/en_us/article/pa5gxn/the-internet-doesnt-need-civility-it-needs-ethics

Muddiman, A. (2017). Personal and public levels of political incivility. International Journal of Communication, 11(21), 3182-3202. https://ijoc.org/index.php/ijoc/article/view/6137/2106

Neuendorf, K. A. (2002). The content analysis guidebook. London: Sage.

Norris, P., \& Inglehart, R. (2019). Cultural backlash: Trump, Brexit, and authoritarian populism. Cambridge: Cambridge University Press. https://doi.org/10.1017/9781108595841

Papacharissi, Z. (2004). Democracy online: Civility, politeness, and the democratic potential of online political discussion groups. New media \& society, 6(2), 259-283. https://doi.org/10.1177/1461444804041444

Rossini, P. (2019). Disentangling uncivil and intolerant discourse. In R. Boatright, D. Young, S. Sobieraj, \& T. Shaffer (Eds), A crisis of civility? Contemporary research on civility, incivility, and political discourse (pp.142-157). New York: Routledge. https://doi.org/10.4324/9781351051989

Roth, Y., \& Harvey, D. (2018, June 26). How Twitter is fighting spam and malicious automation. Twitter blog official. https://blog.twitter.com/official/en_us/topics/company/2018/how-twitter-is-fighting-spam-andmalicious-automation.html

Rowe, I. (2015). Civility 2.0: A comparative analysis of incivility in online political discussion. Information, Communication \& Society, 18(2), 121-138. https://doi.org/10.1080/1369118X.2014.940365

Ruzza, C. (2009). Populism and Euroscepticism: Towards uncivil society? Policy and Society, 28(1), 87-98. https://doi.org/10.1016/j.polsoc.2009.02.007

Stryker, R., Conway, B. A., \& Danielson, J. T. (2016). What is political incivility? Communication Monographs, 83(4), 535-556. https://doi.org/10.1080/03637751.2016.1201207

Sweeney, J. (2018, April 4). The role of social media in the eighth amendment referendum. Digital Training Institute. https:/digitaltraininginstitute.ie/role-of-social-media-eighth-amendment-referendum/

Tait, A. (2016, August 15). Get in the sea: When is a death threat not a death threat? NewsStatesman. https:// www.newstatesman.com/science-tech/social-media/2016/08/get-sea-when-death-threat-not-death-threat

Tracy, K. (2008). "Reasonable hostility": Situation-appropriate face-attack. Journal of Politeness Research: Language, Behaviour, Culture, 4(2), 169-191. https://doi.org/10.1515/JPLR.2008.009

Wojcik, S., \& Hughes, A. (2019, April 24). Sizing up Twitter users. Pew Research Centre. https://www.pewresearch.org/internet/2019/04/24/sizing-up-twitter-users/

Young, I. M. (2000). Inclusion and democracy. Oxford: Oxford University Press. https://doi. org/10.1093/0198297556.001.0001

Zerilli, L. (2014). Against civility: A feminist perspective. In A. Sarat (Ed). Civility, legality, and justice in America (pp. 107-131). Cambridge: Cambridge University Press. https://doi.org/10.1017/ CBO9781107479852

(C) 2021 Nordicom and respective authors. This is an Open Access work licensed under the terms of the Creative Commons Attribution-NonCommercial-NoDerivatives 4.0 International Public licence (CC BY-NC-ND 4.0). To view a copy of the licence, visit https://creativecommons.org/ licenses/by-nc-nd/4.0/ 